\title{
Resistance, Critical Agency and Initiatives of Black Post-School Youth, Facilitators and Organisers in a Black Township in South Africa
}

\author{
Devika Naidoo $^{1, *}$ \\ ${ }^{1}$ Department of Education and Curriculum Studies, University of Johannesburg, Johannesburg 2192, South Africa \\ *Correspondence: Department of Education and Curriculum Studies, University of Johannesburg, Johannesburg \\ 2192, South Africa. E-mail: devikan@uj.ac.za
}

Received: February 14, 2017

Accepted: March 1, 2017 Online Published: April 27, 2017

doi:10.5430/jct.v6n1p97

URL: https://doi.org/10.5430/jct.v6n1p97

\begin{abstract}
The Post-school Education and Training (PSET) policy seeks to address the education and training needs of post-school youth not in education, employment nor training (NEET). The problem of youth NEET has been researched from many perspectives. However, there is a dearth of knowledge about the responses, views and actions of post-school youth NEET living in this precarious situation. This paper analyses the resistance, critical agency and initiatives of youth; organisers; and facilitators at a youth development and organisation centre in a township in Gauteng. The study is framed by the notion of 'critical' agency (Gramsci: 1971) and Bourdieu's concept of 'strategies' that mediate structure and agency. These concepts enable a focus on critical agency that emerge within severely constraining social conditions. Data were collected through the following sources and methods: from a 'youth dialogue' amongst engaged youth; ethnographic interviews with post-school youth themselves; interviews with key individuals such as organisers, leaders and facilitators of programmes; and observations of literacy classes offered at the centre. Data analysis revealed resistant counter discourses amongst the youth to school and current PSET; acceptance of education for employment; desire for higher quality education; and clear ideas of alternative pedagogies. In addition to these counter discourses the paper highlights the critical agency of key individuals in the face of debilitating structural constraints. Implications for the post school education and training system are raised and some recommendations are made.
\end{abstract}

Keywords: resistance; critical agency; strategies; initiative; youth centre; non-formal education; post-school youth

\section{Introduction}

GG Alcock author of Kasinomics writes: eKasi, the lokasie, the South African township, once an apartheid ghetto, is today an amazingly transformed place. The township that was the context of this study does indeed bustle with life on a daily basis. When most people are occupied with various kinds of work, away from their homes, there is a constant flow of young people in the streets engaged in leisurely activities. In discussion with them it was learned that they do this every day. What was most disconcerting was that when they do get work it is menial physically demanding work that they are paid very little for. These youths are part of the three million youth between 18 and 24 in SA not in education, or training or employment. Such youth have been described as part of the precariat - a social class formed by people afflicted by precarity and who suffer chronic uncertainty and insecurity (Standing, 2010). The precariat lack job security, engage in intermittent employment and underemployment leading to a precarious existence. In SA there is a 50\% unemployment rate among people under 25 (Cloete: 2009). This is not unique to SA only but occurs across the world. According to figures from Statistics South Africa, in the second quarter of 2013 the number of youth aged 15 to 24 who are NEET comprised 3.4 million making up 32.9 per cent of persons in this age group (DHET, 2013: 3). To compound the issue these inequalities are racialised: $53.4 \%$ of Black youth from $15-24$ were unemployed by 2009 which was three times worse than the $14,5 \%$ jobless rate of young white South Africans (Cloete \& Butler-Adam 2012). The NEET rate is also gender-skewed, being 29.7 per cent among men and 36.1 per cent among women, thus emphasising the need to focus on the expansion of opportunities for women (DHET 2013). Cloete corroborates the racial and gender aspect by noting 'that structural inequalities continues - the most affected being African and women' (Cloete, 2009:9).

The NEET problem has been explained from a variety of angles and levels. The emergence of the 'precariat' class 
has been attributed to neoliberal capitalism. Within the context of neoliberalism, education policy and practice reproduce systems of exclusion in mainstream schooling (Deuchar, 2012). Within the current neo-liberal economic framework an increasing number of youth are excluded from the formal economy. In SA the marks of colonialism and apartheid are deeply etched onto every aspect of the educational system (Wedekind, 2013) including the post-school education and training sector. The critical postcolonial perspective views the neo-liberal free market approach to economic development and education as a continuation of colonialism (Martin \& Griffiths, 2012). This approach fails to take into account the inequalities and power differentials that have arisen from colonialism and a variant of it in South Africa, apartheid.

The issue of youth NEET has led to government initiatives such as the Youth Employment Accord that includes the existing learnership allowance and the employment tax incentive that encourage, through a tax incentive (SARS, 2014), employers to increase the levels of employment of youth and also contribute to skills development of 'excluded youth'. Then the PSET system aligns with developing post-school youth to cater for a modern economy (DHET, 2013). This is essential not only to take account of the needs of the youth who complete school but also for those who do not complete their schooling; it is equally important in order to cater for the needs of older people, including those who never attended school, who require education and training opportunities in order to live fuller and more productive lives as both workers and citizens' (DHET, 2013: 7). Then there are concerns from a social justice and human rights perspective. The white paper notes that post-school eduction and training 'should also contribute to developing thinking citizens, who can function effectively, creatively and ethically as part of a democratic society. They should have an understanding of their society, and be able to participate fully in its political, social and cultural life' (DHET, 2013). However, these state attempts have made little impact. Kraak (2013) notes state failure in dealing with the youth NEET problem in SA. Kraak has attributed the failure of youth NEET to access the first job to social capital that does not include valuable contacts such as those who are employed. Furthermore, Kraak views this as surprising given the relative success of NGOs operating at the micro level in facilitating access to the first job.

Garza (2015: 44) notes that the White paper on PSET 'addesses the problem of narrow pathways and poor opportunities available for young people who are out of school'. Based on comparison with the American community college system Garza holds that a diversified, differentiated, flexible and affordable post school sector is necessary. The American community college system has the following: open access, low barrier to entry and affordability; diverse programmes that range from access to higher education to community and personal enrichment; flexibility in provision during the day, evenings and over weekends; a local community presence; and the provision of extensive developmental and bridging programmes for underprepared students (Garza, 2015: 44). An additional provision is non-formal education (NFE) that provides educational opportunities to children, youth and adults who have dropped out too early to acquire basic literacy skills (UNESCO, 2013: 55). NFE may cover education programmes to impart adult literacy, basic education for out-of-school children, life skills, work skills and general culture.' (UNESCO 2005).

Much of the research on youth NEET also labelled 'excluded' youth (Cloete, 2009) or part of the 'precariat' class (Standing, 2010) focus on the causes of dropping out of school. The HRDC (2012) highlights the challenges facing youth NEET and the contributing factors. The issue of post-school youth and youth disaffection with education has been explained as arising from innate qualities of the youth themselves or as arising from social experiences. The externalist sociological perspective 'blame young people for their disengagement' (Smyth and Robinson, 2015: 227) and sees such youth as being in deficit either 'individual or familial, that amount to blaming individuals or their backgrounds' (Smyth and Robinson, 2014). The cause of differentiation and inequality are seen as innate and/or material deprivation, cultural and social deprivation (Moore, 2004:18) including poor attitudes, laziness, lack of motivation, low ability, and low IQ (Robinson, 2012: 11). The blame extends to the incapacity of the family to equip their children to benefit from school.

Internalist approaches focus on the processes associated with the school such as 'organisation of the education system ... that may reflect and reproduce class and other division' (Moore, 2004:18). From this perspective, researchers have uncovered reasons given by disaffected youth for dropping out of school. Robinson et al (2012: 11) note the alienating nature of 'doing' high school...large class sizes, rigid timetables, hierarchical structures, didactic pedagogies, punitive behaviour management regimes, poor facilties, measurement and testing, standardisation, lack of creativity, labelling, streaming, irrelevant curriculum, vocationalisation, and poor relations with teachers. Curriculum related factors include social biases in the formal curriculum such as the stereotypical representation of traditional gender roles or of white superiority or the assumption of middle-class cultural values (Moore, 2004: 18); and curricula not related to student's lives (Kirby and Gardner, 2010). Teacher related factors include low 
expectations resulting in a self-fulfilling prophecy of success of some groups and failure by others (Moore, 2004:18) and ineffective pedagogical practices (Kirby and Gardner, 2010). Regulative factors include the control over movement, timetable specifications, interpersonal conflict; and the failure of schools to acknowledge and include ...diverse cultural identities arising form ethnicity and sexuality (Moore, 2004:18). According to (Smyth and Robinson, 2014: 221) the factors that lead to disengagement are: (i) achievement - poor prior learning experiences, absences from school and poor language and literacy skills; (ii) aspiration - an absence of career plans, poor knowledge of labout market opportunities and how to educationally access them, and limited networks (iii) application - poverty, disability, health problems, family commitments, living circumstances, refugee status and (iv) access - poor undertanding of options, low aspirations and confidence, constraints relating to finance, geography or time. Smyth and Robinson (2014: 18) note that disengaged youth 'need space and freedom to pursue their own interests and aspirations' and find traditional schooling constraining and limiting.

Contrary to common sense Smyth and Robinson (2015) note that leaving school 'often has little to do with their academic capacity' (225). Robinson et al found that the catalyst in the case of their informants was the enactment of the policy on Behaviour management in schools, specifically the uniform policy. Not wearing the uniform was seen as breach of the schools code of conduct. Being framed as a problem student for 'being out of uniform' and losing 'good standing' and given 'detention', lead to further punishment such as being barred from attending excursions, end of term functions or reward functions. Students thus felt they were not treated fairly by schools. Another reason given was being bullied at school and no one cared about it.

Often these youth did not feel a sense of belonging or connectedness to the school.Taylor (2012) argues that 'a lack of sense of school belonging can be a destabilising aspect in disaffected students' lives' to the extent 'that they will often seek an alternate sense of belonging' (37). Further that a disconnection from school culture, interpersonal conflict and a lack of classroom support' (Kirby and Gardner, 2010) lead these students to dropping out of school. Jonson et al (2012) suggest that various facets of school disaffection such as perceived injustice or actual victimisation at school can lead to substance abuse or higher amounts of binge drinking and marijuana use. These youth are 'less likely to lead healthy lifestyles, cope with life stresses, find secure work or 'good jobs' (Kirby and Gardner, 2010).

In a previous paper it has been argued that the schooling experience of these post school youth evinced gross neglect that worked mainly to exclude youth who aspire to professional and managerial careers. That SA youth NEET reject education that is 'inferior' and thus drop out of school. They are not disaffected from quality education that abides by the basic paradigm of teaching (Willis, 2000) and socially just schooling (Robinson, 2012). To the contrary they desire education that would provide them with the opportunities to access higher education qualifications and professional and managerial jobs. This research supported views of other researchers (Smyth \& Robinson, 2015) that the issue of post school youth requires not only alternative post school programmes but also attention to schooling practices within formal secondary school education.

A dearth in the literature on post-school youth is knowledge about the responses, views and actions of post-school youth NEET living in precarious conditions. This study explores the responses, views and actions of post-school youth NEET living in a Black township, (designated as 'an apartheid ghetto' a Black residential area during apartheid) plagued by unemployment and related social problems, but within which agency unfolds. This paper highlights the resistance, critical agency and initiatives taken by critical agents amidst overwhelming structural inequalities. It provides an understanding of individual youth NEET that is contextually representative.

\section{Theoretical Resources}

The macro critical perspective holds that education reproduces social inequalities. The agency, resistance and initiatives of individuals in localised contexts are subsumed by the 'big picture'. While not downplaying the significance of the 'big picture' for relating the local inequalities and injustices to the national and global, nor the power of social structures to constrain agency in local contexts, this study focussed on individual actions, discourses and agency in local contexts. Long (2008) argues that 'we need to develop a form of analysis that centers on understanding actors' everyday life struggles that should focus attention on the local sites of tension between structure and agency (Richmond, 2011:387).

The neo-liberal approach to agency emphasises free will and 'freedom from social and structural restrictions in the pursuit of self-expression and self-actualisation' (Kumashiro, 2010:5). Critical approaches redefine agency as actions that are possible within the context of social constraints (Baez, 2000). Bourdieu's (1990: 6) concept of 'strategies' relates structure and agency and shows their interplay in practice. According to Bourdieu, strategies rather than 
'rules', 'model' or 'structure' reintroduces the agents active engagement. De Certeau's argues that everyday life works by using the rules and products that already exist in culture in a way that is influenced, but never wholly determined, by those rules and products. In The Practice of Everyday Life, de Certeau outlines an important critical distinction between strategies and tactics. Strategies are produced by 'producers' those within power structures, such as the state or municipality, the corporation or the proprietor, a scientific enterprise or the scientist. Thus Certeau links "strategies" with institutions and structures of power. Individuals or 'consumers' act within these environments defined by strategies. The subjugated and oppressed employ tactics to resist these strategies.

Critical agency is a complex concept to define. Gramsci's (1971) notion of critical agency refers to 'purposeful, deliberate or designed' action that resists hegemonic practices that ensure and justify the domination of some individuals by others. For Gramsci the subaltern's shift to agency starts with resistance to hegemonic conditions and is followed by action and taking initiative and being responsible . Bignall (2010) in attempting to create a post-colonial concept of agency distinguishes between critical agency and constructive agency. She argues that 'an adequate philosophy of active social transformation requires critical agency and an element of constructive agency. While Critical agency is aimed at the existing, problematic structure constructive agency is aimed at producing a preferred structure, which does not yet actually exist.'

Resistance is the key element of critical agengy (Richmond, 2011). The term resistance is commonly used with a negative connotation to indicate an oppositional action to something that one disapproves or disagrees with (Sanino, 2009). A positive view is that resistance must be promoted rather than repressed or avoided: 'The engagement of resistance - not its repression or its avoidance is critical' (Kindred, 1999). In this view resistance is seen as 'manifesting early forms of agency' (Sanino, 2009). Kindred $(1999,213)$ analyses the different aspects of resistance:

Resistance is a way to say no, but it also expresses a desire for more engaging and less degrading work relations and activities... resistance is not only a contest of authority...but ultimately it is a move toward authorship. It is an act along the path of appropriation and empowerment, or making mine.

Resistence begins with individuals who reject 'common sense' to subvert what is deemed an oppressive social practice (Richmond, 2011). Resistence is the means by which power and hegemony are resisted either discursively (counter discourses) or in terms of social practices (Foucault $1984 \&$ 1976). Foucault noted the possibility of 'acting beyond power' (1984 \& 1976). 'Reverse' discourses seek to subvert powerful discourses, the first stage in challenging meaning and power and the production of new, resistant discourses. According to Foucault 'discourses are not once and for all subservient to power or raised up against it ...discourses can be both an instrument and an effect of power, but also a hindrance, a stumbling block, a point of resistance and a starting point for an opposing strategy' (1990: 100).

Critical agency is often associated with everyday forms of resistance to power (Richmond, 2011: 423) and emphasise the local-local discourses and practices of agents or local agency. A 'daily ethico-political struggle' emerges that creates the conditions for resistance to oppressive power (Richmond, 2011).

The identity of the critical agent is one of a resistant, critical subjectivity - not reactive in the negative sense but as a constructive process opposed to compliance, a new form of subjectivity that is opposed to domination. Critical agency emerges not because of the benevolence of elites, but because of the capacity of subjects and their aspirations (Richmond2011). It is aimed at transformation and emancipation at alterity rather than homogeneity (Blaney and Inayatullah, 2002). Resistance is seen as 'always most effective when localised' (Baez, 2000) as the analysis is more contextually representative.

\section{The Research Context and Background}

Despite the institution of a democratic government and political system in 1994, the township where the youth centre is located is exclusively populated by the Black population group. It is approximately $60 \mathrm{~km}$ from central Johannesburg. Heavy industries such as chemical, iron and steel, fertiliser, power stations are within $10 \mathrm{~km}$ of the residential area. The township has both tarred and dirt roads. It has a mixture of standard small council homes, constructed during apartheid for Blacks as well as individually designed homes. Four schools in the area have closed down due to students attending schools in other areas. The area is noted for substance abuse, high crime rates and unemployment. During work days large numbers of young people walk about in the streets, sit in groups playing cards and other games. The organiser of the community centre thought that the area has around 10000 post school youth who are NEET. They have dropped out of school and according to the organiser 'loiter' on the streets in groups. 
The Youth Development Organisation (YDO) is supported by the benevolent international organisation, Eindhoven and by the local industrial gian, Arcello Mittal. The services rendered at the centre include: advice referral, service referral system, internet access, CV upload; social programme: teenage pregnancy support group, substance abuse workshops, career exhibition; skills development: computer training, life skills training, welding, sewing, entrepreneurship workshops from Monday to Friday. The mission of YDO is to provide economic sustainability and eradicate poverty in their community through the implementation of sustainable livelihoods programmes. The vision is to empower youth, uphold and promote high moral values amongst youth and implement economic development programmes.

Youth who make use of the services and enrol in the programmes come not only from the surrounding area but also from up to $30 \mathrm{~km}$ away. In 2015, 87 students were registered at the centre. A typical day at the centre involves starting at 8am with Life skills lessons followed by workshops on substance abuse, computer literacy classes and sewing classes. With the exception of sewing classes where students pay R700 once off for a three month course, all other classes are free. Around $12-15$ students attend each of these programmes. The computer literacy facilitator runs 6 classes a day for 12 students at a time. Similarly, there are a number of life skills lessons per day. Students attend classes they are able to. The flexibility allows more students to attend according to their own timetables.

\section{Methodology}

This qualitative study sought to understand how post-school youth constructed the situation they found themselves in and the initiatives they took to improve the situation. Informed by case study methodology, data were collected through observations, interviews and document analysis. Data were collected through the following sources and methods: during a 'youth dialogue' with 50 male and female Black youth participants and facilitators to which I was invited. Participants spoke in English or mother tongue and were very forthright and informative about their own experiences to improve their capabilities/skills and gain employment. This dialogue was audio recorded and transcribed in English by the convenor of the dialogue and sent out to all researchers in the team. I read and analysed this transcript in-depth and identified key issues to be followed up in the individual interviews. In-depth interviews were conducted with 10 facilitators/organisers and followed up by informal conversations with students. I interviewed the facilitators of the following programmes: computer literacy, Life skills, sewing and leadership workshops. Observations of computer literacy, sewing, life skills lessons and workshops activities and music centre activities were also done. Field notes were made during observations. The lessons were also audio-taped and transcribed. Participants often code-switched and these were translated into English.

An interview guide with open-ended questions enabled participants to speak about: what led them to becoming facilitators at the centre, what their roles were, why they do it, what are their successes and challenges. The interviews were audio recorded and transcribed.

An initial transcript was chosen randomly and analysed to identify the initial codes. The responses were read and assigned codes that captured their essence. For example, the codes of: awareness of social injustice; attempts to make sense of the injustice; taking responsibility; taking action to respond to the injustice; their sense of achievements; dismay and their challenges were identified. All other transcripts were analysed according to the initial codes as well as inductively for different codes specific to them. These codes led to the categories: resistant discourses to school and current PSET; ideas of proper education; and actions of critical agents.

Ethical approval was given for the study by the university ethics committee and the research was guided by the committee's guidelines for ethical research practices such as full disclosure of the purpose of the study, upholding anonymity and confidentiality as well as liberty to withdraw from the study if necessary. All participants engaged fully in the study.

The concept of critical agency has been operationalized to include resistant discourses as a part of agency; individual's actions to address oppressive conditions; and achievements of critical agents that furthers social justice within the context.

\section{Resistance, Critical Agency and Initiatives of Black Post-School Youth, Facilitators and Organisers}

The findings will be presented in three main sections: resistance to current education; firm ideas on good education; and purposeful and deliberate actions taken by individuals. 


\subsection{Resistance to Current Education}

\subsubsection{Stratification}

Participants were aware of and against the dual stratified system of education in SA. This was evident to participants in the obvious material and support inequalities in private and public schools. One of the participants noted 'the current system exacerbates inequality by maintaining the status quo between those who have and those who don't have'. Diana thought that private schools are much better in comparison to public schools because they guarantee the necessary support and attention to struggling learners.

There was also a sense amongst participants of the education system being somehow responsible for their current situation. In this regard Vusi declared that 'privatising education means that we are saying some people should succeed and others should not succeed'.

The provincial inequalities in achievement were also noted. According to one of the participants the current provincial government was failing them by not providing them with equitable educational opportunities as compared with other provinces:

Our government here is also failing us somehow. Consider education in Free State and how well they did with their matriculants last year because of their provincial investment in education. Gauteng structures are failing us.

They were also aware of the stratification of the curriculum in Further Education and Training Colleges (FETCs) and universities and that while the PSET system encourages their enrolment in FETCs the qualifications and courses that they want to study are offered in universities:

Most courses we want to study are not available in FETCs, they are in universities.

If you want to become a teacher, you will choose a university instead of a college.

The participants noted the narrow curriculum of the FETCs that are business related:

Most courses in our FETCs are business related which is limiting despite the availability of bursaries and access to funding in FETCs.

\subsubsection{Concern over Schools Closing Down in the Area}

Participants were aware of the decline of schooling opportunities in the township and expressed their dissatisfaction with schools closing down:

In fact, many schools are closing down. Why are our schools allowed to be closed down?

To prove his point the participant pointed out that the venue in which the youth centre is being housed was once a primary school.

YDO premises are one such school that was closed down and the property leased out to YDO by the Department of Higher Education to run their programmes from the school.

The participants were also resistant to educators in the community sending their children to private schools. One of the participants asked:

Why are our educators taking their kids to private schools instead of public schools?

Their view was that schools in the community schools ought to be upgraded with more cultural and extramural programmes and the necessary resources:

Why not equipped them with more cultural or extramural programmes? We have the facilities and the space to resource our schools with sport courts and music lessons.

The participants declared that they need an education that responded to their needs as the current provision did not meet them at present. In one of the participant's words:

The system must come down to our level. It must let us study what we want to, what will develop our talents.

\subsubsection{The Myth of Qualifications Leading to Employment}

The youth were sceptical about the ideology that further education and training would get them employment. They gave examples of peers who achieved qualifications and were either not employed or not earning a fair salary. For example, Pindi knows a bio-technologist who is employed as a delivery person and who earns a pittance. According to Pindi, this is an injustice because his 'friend' is a qualified bio-technologist and his salary is not commensurate 
with his qualifications. One of the participants declared that he would rather earn a lower salary without studying than study and then not earn commensurately:

I would rather get any paying job to put food on the table than study a qualification that will still pay me a salary for less qualified people.

\subsubsection{Concern for Youth NEET and Guilt over Letting Parents Down}

At the start of the group dialogue Lerato reminded the group of youth NEET in the community:

this dialogue is not only for our benefit as we are seated here, it is also for the betterment of those youth out there in our community.

The youth feel overwhelming guilt about letting their parents and gurardians, who struggle to send them to school, down. They said that their parents worked so hard to earn money to send them to school and that they feel terrible about having disappointed them. The poem composed and performed by Themba titled "in the beginning" reflected their guilt. The theme of the poem highlighted the plight of a hard working mother who occupies herself as an informal trader to earn money to fund her child's education. However, her efforts are thwarted by the same child who allows the opportunity of education to escape him because of making wrong choices. Long after the mother has passed on, the individual continues to regret his choices and the fact that he has not achieved much.

The relational component between the son and mother is highlighted. The son has not only made 'wrong choices' but has also not honoured his mother's efforts to provide support.

\subsubsection{Rejection of a 'Eurocentric' School Curriculum}

The participants are well aware of a curriculum that denies their lives and experiences. One of the participants, Tsepo, assertively spoke about formal education that does not acknowledge nor recognise the realities of Black communities. His own education in a white Catholic school did not refer to nor acknowledge those issues. He thus rejected white schooling and joined the centre where he became a facilitator. His gaol is to 'develop talent' of Black students at the centre. Working at the centre 'gave his life meaning'.

\subsubsection{Poor Quality Schooling}

Participants were contemptuous of the poor quality schooling they were subjected to. They questioned why they did not get career guidance in school and why their teachers' didn't come to school regularly. They were aware of the trend that 'on payday the teachers don't come to school'. Then they felt neglected by teachers who although present in the classroom did not teach their knowledge areas. Although she lived in a shack, has transcended it - reads the newspaper, is knowledgeable, scorns those 'who burn schools and libraries',

\subsubsection{Negative Perceptions of Teachers}

Generally, the youth participants have a very negative view of their teachers. One of the participants experienced his teachers more like policemen who spoke to students as if they were prisoners:

My teachers were like policemen - they spoke to us as if we were prisoners

The majority of the participants perceived their teachers as 'hating' them and always 'picking' on them:

The teachers hated me, always picked on me in class. One would make me read aloud class because he wanted to ridicule me.

In one of the schools test and examination results were posted on the noticeboards that made them feel embarrassed:

Our results were put on the notice board, I felt embarrassed.

\subsubsection{A Diluted Curriculum}

The post-school youth were also aware of a non-academic diluted curriculum taught to Black students. Participants viewed a rich academic and extracurricular curriculum as essential for a proper education. They rejected being taught less than in 'white' schools. Themba started his high school education in a 'white' school but after grade 10 had to move to a public school due to financial constraints. He was able to experience the great variation in quality at public and private schools. He articulated his experience:

There was a huge difference. A grade ten student (in the white high school) already knows about four books of Shakespeare but public school learners encounter them in matric, with Macbeth. We received "student companions" which are provided by the school for free. They contain a variety of broad factual information and learners use it to 
refer. Kasi learners are not familiar with it (student companion). It's not that I undermine Kasi but white schools enjoy various privileges which set their education apart from 'Kasi schools'.

Participants saw it as a human right to be exposed to a curriculum that is rich and varied, similar to the curriculum of private schools, so that they are provided with a range of options that they could pursue over and above an academic route:

Even their extramural activities are richer than what is available in 'Kasi schools'. This gives them options in case a learner is not strong academically, then the learner can take photography as an alternative because it was introduced in school."

\subsection{Post-school Youth Views of a Good Education}

\subsubsection{An Education that 'Puts Food on the Table'}

Much of the group dialogue focussed on participants views on proper education. A general view is that 'a proper education is the ability to study what I love and be able to earn a living from it'. Education that puts 'food on the table' was strongly supported. The participants discussed the real purpose of education. Was it 'about advancing other people's ideas, or about having something to eat on the table. They see no point of education if unemployment is still increasing.

Tinto expressed wishes for an education that enables individuals to operate small businesses whilst they are studying. This would assist them when their hard won qualifications do not materialise into employment. He offered the examples of the Indian and Chinese people as communities that are business conscious despite the presence of a full time job.

\subsubsection{A Balanced Curriculum}

Concern was expressed over a humanities or science focussed curriculum and an imbalance in theory and application of theory. Bongani believes proper education to be 'an education that teaches everything from science to art. It incorporates practical application of theories learned in class such as enabling learners to start businesses as part of the lesson in Business subjects'.

\subsubsection{Based in Ubuntu}

The participants desired an education that will 'also teach us about our own culture of Ubuntu, not detach us from those principles'. Tulani was of the view that 'the problem with this current model is that we are taught everything about everything and nothing about ourselves. Going inside of ourselves and taking that out and using it to learn something' is what ought to be done.

\subsubsection{A Larger Role for Parents, Family and Home}

Participants also attributed a bigger role for parents, family and home. Thus, participants were of the view that: 'proper education begins at home with the parents'. According to the participants 'proper education starts at home'. One of the participants was of the view: 'my behaviour and interactions with the outside world was shaped at home before going to school. Another participant was of the view that information from parents about the child's strengths and abilities is a key aspect that is not acknowledged by the system. Parents should play a greater role in identifying the 'gift' of the child and provide this information to the school so that 'a suitable education' is provided:

"Parents must be able to identify the gift of the child at an early age. Based on the information from the parent, a child will receive a suitable education experience".

Participants were also aware of the influence of lack of role models in the family for educational achievement. According to Prince:

If senior members of the family have not yet achieved educational success, children in that family will tend to undermine their own abilities to attain an education.

\subsubsection{More Focus on Arts and Sports}

The participants noted their frustration at lack of differentiation of the curriculum and being channelled towards more academic studies. Thus a participant declared:

Frustration occurs when a child who wants to be a singer is steered towards an engineering career. This is what we see happening today. 


\subsubsection{Well-Resourced Schools}

Participants conveyed that proper education depends on 'well-resourced schools with textbooks and laboratories, and proper educators'. To elaborate further a participant who failed science mentioned the lack of science apparatus for learning science through practical experiments:

During practical lessons, there is limited equipment between the learners and this resulted in only two learners actually participating in the experiment whilst the rest of us agree with everything without much involvement.

\subsubsection{Teachers Who Are Not 'Lazy'}

The youth were very forthright about the kind of teacher they required: a teacher who is not lazy and wants to teach and not sabotage their education. In a participants words:

If a teacher is lazy you won't be educated since you are there to learn from the teachers, we can't teach ourselves".

Our learning is also shaped by the teachers we have. If a teacher does not want to teach, he or she is sabotaging education similar to a young person who does not want to receive the knowledge teachers are giving.

\subsubsection{Teachers Who Would Explain Difficult Subject Knowledge}

Participants recalled teachers who came to class but did not teach them:

I recall my science teacher from school. He would arrive in class with thick textbooks to be shared between at least five learners (due to shortage of textbooks) with the activities already ticked and accompanied by the class work. He would not explain the work but we would be expected to complete the activities. The next day he wants us to do corrections and we don't know the work. Therefore, we agreed with all his corrections since we did not understand the work. I failed science" as a result.

\subsubsection{An Inclusive Education}

A proper education is 'accommodative to all including disabled people who are still largely marginalised in terms of access.' Participants agreed that many disabled people in the township are not accessing various educational opportunities because there is inadequate provision for and awareness of them.

\subsection{Actions of Critical Agents}

The organisers of the community centre and facilitators of the programmes were of the view that the youth NEET were being 'neglected'. One of the organisers (Thato) observed the 'loitering' that post-school youth were engaged in, in the area. They would 'congregate in groups of $8-10$ in the streets', play cards and other games and consume alcohol and other mood and mind-altering substances. According to Thato, weekdays are no different from weekends. 'If you go into the area you will think it's a weekend'. Indeed, observations did show groups of youth and older men sitting on the side of the street in circles. This 'loitering' worried Thato. He knew that young people faced many issues: 'being school dropouts, being unemployed, being stuck' but these problems were not 'being addressed' and there was no hope of them getting 'sustainable livelihoods'. The lack of a youth care and support centre in the community showed that no attention was being given to youth NEET. Thato took responsibility to set up a youth centre in the community. He was approached by the Youth Development Council YDC to start an advice centre in the township. He started an informal addressing of these problems in homes, but found this 'very challenging' because there would be noise and 'children crying'.

He then saw that a primary school had closed down in 2012 and was being vandalised. He applied to the Department of basic Education and Training to use the school premises as a venue for youth development. The Department then leased the school to him for this purpose at no cost. He became a key person in lobbying, organising and starting the Youth Development Organisation RYDO) and registered it with the Department of Health and Social Development in 2009. With a venue secured and a team of volunteers he did a survey to find out 'what can we do?' and 'what the community wanted to do in the facility'. As the lead researcher, he found that there were five main categories of need:

- an advice centre that would assist with CV writing, uploading information, internet access, daily newspaper

- a social development centre

- a skills development centre such as computer literacy and programmes such as MS office

- an entrepreneurship development centre and

- an arts and culture development centre. 
He required sponsors and searched the internet and came across a 'social improvement foundation' in the Netherlands. He wrote and sent them a profile of his idea of a YDC and told them of what he wanted to do. To his amazement they were very interested and came to the centre to see for themselves. When they came to the centre he told them about his plan to offer programmes to youth that will make them more employable such as: journalism, carpentery, computer literacy, photography, welding, music and singing professionally. They asked Thato to develop a proposal which he did and sent in. Through that initiative taken by Thato, the foundation donated 50000 rand. Thato used this money to purchase office furniture and 6 computers and develop the advice centre.

Subsequently, Thato approached the SASOL foundation with 'what they can do for YDO?' A senior person from SASOL then visited YDO. Thato undertook to do a survey and found that there were around 1000 women in the area with 'many children' who were sole breadwinners but who were not employed. He 'filled in a proposal form' and in five weeks was donated 120000 to buy sewing machines. A programme was started to teach women to sew. Part of this was to make overalls for the surrounding heavy industries in the area. After YDO was written about in the local newspapers, Thato was approached by Randwater and sponsored with 100000 to purchase equipment for photography.

Many of the participants were not provided with career guidance. Lerato's narrative provided much evidence of individual engagement to take responsibility for her own career. Lerato admits that she had to 'hustle a lot'. She was called piglet girl in school because her family kept pigs. She lived in a shack and her mother told her that 'she will wash clothes' to survive. Lerato resolved never to let that happen. Lerato attended a public high school where the teachers 'sometimes didn't come to school; 'come to the classroom, but don't teach'; don't come to school on payday' and did not 'make available past exam papers to students'. After matric Lerato was confused about what to do and then chose boiler-making to please her dad. She could not finish due to lack of finances. She then decided to study Law through UNISA and enrolled for the bridging course to please her mum who is a clerk in the local court. She thought that she would become a stenographer in court. She hopes that the computer literacy certificate she gets will assist her in her application for admin jobs. She 'sat in class and got bored'. She failed the second year and dropped out. Lerato is 26 years old and enrolled in the Life Skills and computer literacy classes at the centre. She travels $35 \mathrm{~km}$ from her home to the centre and then $35 \mathrm{~km}$ back home at a cost of R300 per week. Her vast general knowledge from reading widely and her excellent language skills in English were very evident in the Life Skills class. She applied for a part-time job at Mathew Goniwe school of leadership where she is employed on a part-time basis to facilitate workshops on topics such as gangersterism, sexual abuse, safe sex. She also speaks to parents about the Annual National Assessments and about how to help their children prepare for assessments. She attends the leadership programme at the centre on Tuesdays for one and half hours and says 'it's the best'.

Linda, a reserved and serious minded 18-year-old attended a 'no fees' high school. She faced financial and gender related constraints. She was able to pay R200 registration fees but unable to buy the equipment she needed. She was forced to drop out of high school in 2014 after grade 10 because she did not have money to buy equipment for her mechanical and graphical engineering subjects. She enjoyed school and subjects like Mechanical and graphical engineering, physics, Maths. She had a stable school experience until grade 10. Then her grandmother passed away and her parents used the money for her funeral. The traditional practice is to foreground funerals that are very costly. While Linda understands this she also feels neglected by her parents who ought to provide for her to complete her schooling. The support given to orphans could not be given to Linda as she is not an orphan. She could not borrow equipment for tests especially as all grades wrote tests at the same time. Then Linda disclosed that being a girl she did not steal equipment while the boys survived by 'stealing equipment and exchanging them'. She had her sights set on studying architecture or civil engineering at university. She felt very disappointed by her parents and the school but happier that she 'had found something to do' at the centre, where she is enrolled in sewing classes, fashion design, computer literacy and Life Skills. Her cousin made her aware of the centre and she travels $30 \mathrm{~km}$ from Evaton to the centre every day at a total cost of R16 per trip.

\section{Discussion and Conclusion}

It would be naive to deny the influence of apartheid structured inequalities on youth agency in the township. The marks of colonialism and apartheid are deeply etched onto every aspect of the educational system (Wedekind, 2015) including constraining the agency of Black youth in the township. The range of PSET opportunities that have been made available for youth in the township must be acknowledged. However the formal PSET provision has evaded the majority of youth enrolled at the centre. The general view of the participants that the current PSET does not meet their needs in their circumstances requires further attention. 
It is well known that SA has a bimodal education system with $70 \%$ of schools being dysfunctional. The continuing stratification of education in public and private schools, the degrading and closing down of schools in the township, the restricted curriculum of FETCs indicate a system that is designed to reproduce structural inequalities. The majority of youth in this study have experienced first-hand dysfunctional apartheid regulated schooling. The participants provided wide-ranging evidence of how the dysfunctionality of their schools characterised by high levels of teacher and learner absenteeism, low levels of teacher and pedagogical content knowlede, limited parental involvement, poor levels of administrative and academic support from education authorities noted by Wedekind (2013) have impacted their schooling and that were contributing causes of them exiting the schooling system without graduating.

Those who enrolled with the view of finding employment faced the reality of not finding work or being forced to take on more menial jobs related to the qualification. The post school youth attest to being unemployed and not being able to find employment inspite of having obtained qualifications. In this context there is ample evidence of Wedekinds (2013) inference that within the current neo-liberal economic framework an increasing number of youth are excluded from the formal economy. The youth did experiment with informal trading but found it demeaning and meaningless for their view of themselves as future professionals. From the more instrumental and extrinsic position of averting 'the time bomb' by providing opportunities for work and life skills post-school youth find the PSET system wanting. From the human rights and social justice position the current post-school youth provision fails to provide sufficient diversified opportunities for reintegration of post-school youth into the education and training system. The words of one of the participants crystallizes the view of post-school youth to the PSET provision currently: 'the system must come down to our level'. The findings show that youth resist what has become known as 'warehousing' (Wedekind, 2013).

For a range of reasons the PSET provision fails to reach post-school youth in the township. These youth thus seek learning opportunities in youth centres. Garza (2015) notes that the White paper 'addesses the problem of narrow pathways and poor opportunities available for young people who are out of school' (44). The YDO programme provides some flexibility in provision in that Computer Literacy and Life Skills has four classes per day and students could attend any class that fitted their personal time-table. It could be expanded to classes during evenings and weekend. It has a local community presence, has open access and is very affordable. The facilitators who have first-hand knowledge of post-school youth in the area also require support. While the centre provides a diverse range of programmes it could be expanded to include more personal development programmes and extensive developmental and bridging programmes for underprepared students.

The PSET system could include a nor-formal component. Non-formal education (NFE) provides educational opportunities to children, youth and adults...who have dropped out too early to acquire basic literacy skills (UNESCO, 2013: 55). This could include personal enrichment programmes that will develop 'thinking citizens, who can function effectively, creatively and ethically as part of a democratic society'. From the example of the American community college system, NFE and the views of the post-school youth in this study personal enrichment programmes that are aimed at personal enhancement and not instrumental for employment would be welcomed by post-school youth.

The counter discourses and actions of critical agents shows that marginalisation, exclusion and injustice are being resisted discursively and in terms of social practices. The substantive counter discourses indicate resistance that originates from personal experiences with the education system and from discussion with other youth who have found ways to work around their disaffection and engage more meaningfully. Post-school youth do show partial understanding of the political, social and historical conditions that contributed to their situation. This is akin to Willis's 'partial penetration' where the 'lads' know their future fate and deliberately reject schooling. Post-school youth are aware of individual examples of individuals who are qualified but have not been sucessful in the labour market. They are also aware of the inequalities in material and intellectual resources in their schools and private schools. These post-school youth have a range of interests such as learning to play hockey, to play musical instruments, to be stage and movie actors that should be encouraged and provided for. The lack of structures to ensure such educational opportunities for post-school youth impedes their potential to participate fully in its political, social and cultural life' (DHET, 2013). While there was mention of 'white' schools being better the participants did not attribute the exclusion of Black youth to racist apartheid policies. This partial awareness result in youth blaming themselves for their situation and the suffering it bestows on their families.

The study also highlights the attempts of critical agents as organizers and facilitators to provide a range of learning activities. The study shows that youth NEET engage in social discourse to understand their conditions and position 
as youth NEET. Through such discourses post-school youth engage with peers to identify possible causes for their situation as not only 'wrong choices' made but also the stratification of education into a high quality and costly private education for the children of the rich and neglectful and restricted and poorly resourced public education for poor Black children. In this regard, Kindred pointed out that resistance expresses a desire for more engaging and less degrading work relations and activities. Through such resistant discourses post-school youth have been able to situate their condition in historical factors, resist processes of exclusion and marginalisation and become agents who actively take initiative to work on their education. Gramsci noted that the subaltern is no longer just resistant but an agent that takes responsibility and initiative. Kindred notes that resistance is 'an act along the path of appropriation and empowerment, or making mine'. The deliberate actions of key critical agents led to the establishment of a youth centre that provided support for youth NEET in the area. The individuals who participate in learning at the centre have also made a conscious choice to change their lives.

The Centre provides crucial support to post-school youth, is a safe haven that helps them to 'recover integrity in their everyday life and reconstruct legitimacy ...from power and structure' (De Certea, 1984). It also shows an alternative way to provide educational and training opportunities for post-school youth not engaged in education and training. While the argument that in the current neoliberal climate such provisions obstruct the development of a policy driven socially just system might be made, the role of centre in the everyday life of post-school youth in a Black township should not be underestimated.

The organisers and facilitators estimated the number of post-school youth to be around 10000 in this area. A glaring gap was the lack of sound data about post-school youth in the area. Meeting the needs of post-school youth requires authentic data about each post-school youth. This would facilitate personal counselling and advice of possible entry and pathway in the stystem, job opportunities, apprenticeships and learnerships in the area that would provide better transition from school to post-school education and training to employment. From the post-school youth experiences of trying to gain employment a number of missing links have been identified that calls for an integrated system that supports the transition from education and training to work experience to employment and to ongoing learning.

This study that focussed on critical agency in a local site enabled an understanding of post-school youths' everyday life struggles, discourses and actions. The reconceptualization of agency, not as free will, but as actions that are possible within the context of constraining social structures enable highlighting the tension between structure and agency (Richmond, 2011:387). It highlights the precariatness of the lives of youth NEET as impacted by current neo-liberal regulatory discourses, their critical agency of engaging in learning opportunities at the YDO and their desire to also further engage in personal enrichment activities should they be available. In spite of being constrained by lack of financial resources these youth NEET exemplify Gramsci's: 'it feels itself to be responsible because it is no longer resisting but an agent, necessarily active and taking the initiative'.

\section{References}

Alcock, G. G. (2015). Kasinomics: African Informal Economies and the People Who Inhabit Them. Johannesburg: Tracy MacDonald Publishers.

Appadurai, A. (1996). Modernity at large. Minneapolis: University of Minnesota Press

Baez, B. (2000). Race-related service and faculty of colour: Conceptualising critical agency in academe. Higher Education, 39, 363-391. https://doi.org/10.1023/A:1003972214943

Cloete, N. (2009). Synthesis. In Cloete, N. (ed.), Responding to the education needs of post-school youth. Determining the scope of the problem and developing a capacity building model. CHET: Wynberg.

Cloete, N., \& Butler-Adam, J. (2012). Match policy with reality and young people stand a chance. Mail and Guardian 2012/08/10

De Certeau, M. (1984). The Practice of Everyday Life. Berkeley: California University Press.

Department of Higher Education \& Training. White Paper for Post-school Education and Training. Building an expanded, effective and integrated post-school system. As approved by cabinet 2013. DHET: Pretoria

Deuchar, R., \& Graham, L. (2012). Re-engaging the disengaged: Challenging the dominant policies and school culture that exclude and marginalise young people. International journal of school disaffection, 9(2), 3-5. https://doi.org/10.18546/IJSD.09.2.01

Fischman, G. E., \& McLaren, P. (2005). Rethinking Critical Pedagogy and the Granscian and Freirean Legacies: From Organic to committed intellectuals or Critical Pedagogy, Commitment, and Praxis. Cultural Studies - 
Critical Methodologies, 5(4), 425-447. https://doi.org/10.1177/1532708605279701

Foucault, M. (1979). Discipline and Punish: The birth of the Prison. New York: Vintage Books

Garza, A. (2015). American Community Colleges. In Research Bulletin on Post-School Education and Training. No 3. DHET: Pretoria.

Gramsci, A. (1971). In Borg, C., Buttiegieg, J. \& Mayo, P. (Eds.), Gramsci and education. Lanham, MD: Rowman \& Littlefield. (41- 66).

Human Resource Development Council. (2012). Challenges facing youth who are neither in Employment, Education nor Training (NEET) in South Africa. Pretoria: HRDC.

Jonson, C.L., McArthur, R., Cullen, F.T., \& Wilcox, P. (2015). Unravelling the sources of adolescent substance abuse: A test of rival theories. International journal of school disaffection, 9(2), 53-90. https://doi.org/10.18546/IJSD.09.2.05

Kindred, J. B. (1999). "8/18/97" Bite me: resistance in learning and work. Mind, Culture and Activity, 6(3), 196-221. https://doi.org/10.1080/10749039909524726

Kirby D., \& Gardner M (2010). The schooling they need: Voicing Student Perspectives on their fourth Year in Senior High School. Canadian Journal of Education, 33(1), 108 - 139.

Klein, R. (1999). Defying disaffection: how schools are winning the hearts and minds of reluctant students. Stoke-on-Trent: Trentham books.

Kraak, A. (2013). State failure in dealing with the NEET problem in South Africa: Which way forward? Research in Post Compulsory Education, 18, 77-97. https://doi.org/10.1080/13596748.2013.755819

Martin, F., \& Griffiths, H. (2012). Power and representation: a postcolonial reading of global partnerships and teacher development through North-South study visits. British Educational Research Journal, 38(6), 907 -927. https://doi.org/10.1080/01411926.2011.600438

Moore, R. (2004). Education and Society - Issues and explanations in the sociology of education. Polity: Cambridge.

Perold, H. (2012). Viewing post-school youth education from a youth perspective. In Perold, H., Cloete, N., Papier, J. (eds.), Shaping the future of SA's youth: Rethinking post-school education and skills training. African minds: CHET.

Richmond, P.O. (2011). Critical agency, resistance and a post-colonial civil society. Cooperation and Conflict, 46(4), 419-440. https://doi.org/10.1177/0010836711422416

Robinson J., Smyth J., Down B., \& McInerney, P. (2012). Pushed out, shut out: addressing unjust geographies of schooling and work. International journal of school disaffection, 9(2), 7-24. https://doi.org/10.18546/IJSD.09.2.02

Sannino, A. (2010). Teachers' talk of experiencing: Conflict, resistance and agency. Teaching and Teacher Education. 26, 838-844. https://doi.org/10.1016/j.tate.2009.10.021

Smyth J., \& Robinson J. (2015). Give me air not shelter: critical tales of a policy case of student re-engagement from beyond school. International Journal of Educational Policy, 30(2), 220-236. https://doi.org/10.1080/02680939.2014.945965

Standing, G. (2010). The Precariat The new dangerous class. Kindle edition: Bloomsbury academic.

Taylor, M. F. (2012). As long as you're resilient you'll succeed: school disaffected adolescents' perspectives on their willingness to engage in high injury-risk graffiti-writing activities. International journal of school disaffection. 9(2), 37-52. https://doi.org/10.18546/IJSD.09.2.04

Wedekind, V. (2013). Education, training and the precariat: An overview of the South African Education and Skills landscape. Retrieved from http://www.dhet.gov.za/brics/Content/Papers.

Willis, P. (2000). Learning to Labour. Why working class kids get working class jobs. Ashgate: Surrey England. 